\title{
Client Perception on Quality Improvement in Health Care Services
}

\section{and Patient Satisfaction}

\author{
Davoud KZ* \\ Professor of Public Health Sciences, School of Health, Safety and Environment, Iran \\ *Corresponding author: Davoud Khorasani Zavareh, Professor of Health, Safety and \\ Environment, Shahid Beheshti University of Medical Sciences, Iran, E-mail: \\ davoud.khorasani@gmail.com
}

Letter to Editor

Volume 1 Issue 2

Received Date: October 16, 2017

Published Date: October 20, 2017

DOI: $10.23880 /$ phoa-16000111

\section{Letter to Editor}

In recent years, attempting to improve patient satisfaction by proper healthcare services have become a popular way for customer service initiatives [1]. In addition, failure to provide patient expectations may lead to their dissatisfaction as well as their poor compliance $[2,3]$. This is more important in emergency ward, because of a lack of unplanned nature of various victims' attendance at this ward, which should provided critical care for a broad spectrum of illnesses and injuries [4]. Accordingly, the emergency ward is one of the most important hospital departments and approximately comprises around $80 \%$ of all hospital patients. Moreover, due to pediatrics vulnerability, some of which can be lifethreatening and required prompt and proper health care services delivery by emergency personnel. Qualitative approach open new window to clarify current barriers and potential facilitators to provide quality improvement in health care delivery in emergency department, however, little studies is found to use this approach [5]. Moreover, client perception is important source for quality improvement of health care services [4]. Accordingly, this study was designed to explore client perception on barriers-to and facilitators-of quality improvement in health care services delivery and patient satisfaction in an Iranian hospital.

A qualitative approach using purposeful sampling was performed to explore client perceptions those attended at Shahid Motahhari hospital in Urmia, Iran. Data collection was conducted between September 2011 and October 2012. Seventeen semi-structured interview with pediatrics family members was employed to gather the data. Thematic Content Analysis was used to analysis the materials.

Finding indicated that the most important factors affect on client satisfaction and the quality of health care was the speed of the services delivery made by emergency personnel as well as personal behavior and their reaction with patients and their family members. Finding from the other study also indicate that the characteristics of health care providers or organizations result in more "personal" care which are associated with higher levels of patient satisfaction. Furthermore, some other studies indicated that more personal care in the hospitals will even result in better communication as well as more patient involvement, and then better quality of care [6]. Moreover, improving nurses skills in this study also was emphasized by clients, which is in line with the other study that showed that training and nurse skill can improves patient satisfaction [1,7]. It is important to note that hospitals equipments and new technology were less emphasized by participants in this study. However, most participants pronounce that proper and enough emergency ward space are important factors that can improve the quality of health care services.

As a conclusion, findings of this study indicated that based on family members perceptions, the most important factors that affect quality of the health care delivery related to the personnel reaction and their skills in health services delivery, by means of speed of health services that can be improved by continuous educational plan. 


\section{References}

1. Mayer T, Cates RJ, Mastorovich MJ, Royalty DL (1998) Emergency department patient satisfaction: customer service training improves patient satisfaction and ratings of physician and nurse skill. J Healthc Manag 43(5): 427-440.

2. Whiteley J, Goodacre S (2013) Patient expectations of minor injury care: a cross-sectional survey. Emerg Med J 31(7).

3. Khankeh HR, Khorasani Zavareh D, Johanson E, Mohammadi R, Ahmadi F, et al. (2011) Disaster health-related challenges and requirements: a grounded theory study in Iran. Prehosp Disaster Med 26(3): 151-158.
4. Khorasani- Zavareh D, Mohammadi R, Khankeh HR, Laflamme L, Bikmoradi A, et al., The requirements and challenges in preventing of road traffic injury in Iran. A qualitative study. BMC Public Health 9: 486.

5. Cleary PB, McNeil (1988) Patient satisfaction as an indicator of quality care. Inquiry 25(1): 25-36.

6. Khankeh H, Khorasani-Zavareh D, Azizi-Naghdloo F, Hoseini MA, Rahgozar M (2013) Triage effect on wait time of receiving treatment services and patients satisfaction in the emergency department: Example from Iran. Iran J Nurs Midwifery Res 18(1): 79-83. 